\title{
The Design and Implementation of Integrated Control System for The Heterogeneous Remote Terminal Devices
}

\author{
Jeong In Park ${ }^{1}$ and Jin Tak Choi ${ }^{2}$ \\ Dept. of computer science Eng., Incheon National University, Korea \\ jipark@atec.kr ${ }^{1}$, choi@incheon.ac.kr ${ }^{2}$
}

\begin{abstract}
Currently the multimedia contents and various terminal devices owned by public agencies or private companies are operated separately by their manufacturer This can make an immediate action impossible in the event of failure in equipment or contents due to the lack of integrated management, and it can also cause a lon of administranve costs for the maintenance of equipment for each type. In addition, the ineffective magnagement of contents brings about such problems as errors, duplication andinconsistencyin the contents. To solve these, construction of an integrated management system as well as an efficient, low-cost operational system is required. The system $p$ oposed in this paper integrates and controls the remote terminal devices, and it implemented in a multicast way. For each of many different devices in remote locations such as set-top boxes, kiosks and speakers, functions including broadcast schedule edition, multimedia playback automation and subtitle display configuration are controlled directly at the centrat system. The system has been developed mainly on the algorithm of Middleware for multicasting large amounts of data and centralized group management.) As a resum of the test in conjunction with the actual devices, this proposed prograne colla easily integrate the heterogeneous terminals.
\end{abstract}

Keywords: multicast, remote terminal control, heterogeneous Middleware and integrated control

\section{Introduction}

At public agencies, hospitals, schools and other institutions, the promotional contents from the informational screens, speakers and kiosks consist of mainly multimedia contents including audio and video. However, the hardware terminal devices which provide such multimedia contents are not integrated with each other. Since they are operated individually, an immediate action is impossible in the event of failure in the contents or equipment, which can also result in a great deal of maintenance costs by having to proceed the job for each type $[1,2]$.

In order to overcome these problems, the informational contents should be integrated and managed by automated scheduling in the center. In other words, sound source contents should be transferred to the private and public locations, videos or images to the institution's public relations, and simultaneously broadcast or subtitles to the fire or emergency medical services in the event of an emergency. Furthermore, in case of a remote control needed, solutions to multimedia content services are required to be appled flexibly to versatile work which can be resolved by using CCTV [3].

The system proposed in this paper is a multicast-based control module for integrating multimedia contents and remote terminal devices. The range of development is as follows: 


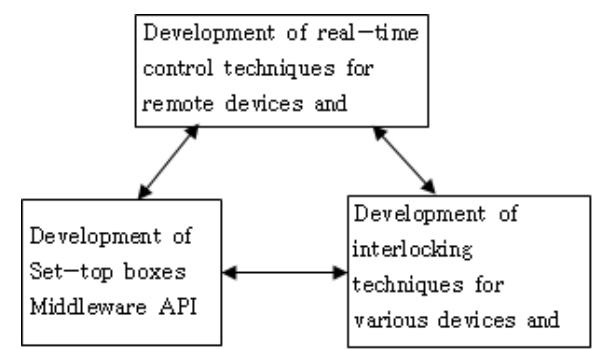

Figure 1. Overview of System Development Scope

As shown in Figure 1, the proposed system aims to develop a multicast-based management module which integrates and controls a variety of multimedia contents andrembte terminal devices and to provide an environment, by connecting with real devices and testing, where heterogeneous terminals can be easily integrated.

\section{Proposed Model of System Services}

\subsection{Overview of Services}

The system proposed here ensures high efficiency and low cost by developing a module which integrates and controls a wide variety of multimedia contents and remote terminal devices.


Figure 2. Target system configuration

It is implemented to provide multimedia playback service for heterogeneous devices on a variety of dynamic scheduling set up by the administrator and multicasting service of large volumes of data by centralized group management for real-time controlling in case an emergency occurs [4].

That is, the system, after individual or batch scheduling for multimedia playback at various remote devices, transmits a batch announcement or emergency message to all the other remote devices connected in the event of an emergency. The scope of system implementation details is shown in Table 1. 
Table 1. Scope of System Development in detail

\begin{tabular}{|c|c|}
\hline Development & Description \\
\hline $\begin{array}{l}\text { Real-time control } \\
\text { technologies of remote } \\
\text { devices and contents }\end{array}$ & $\begin{array}{l}\text { - emergency / reservation / common / individual scheduling of equipment and contents } \\
\text { - real-time monitoring, fault management, equipment control and broadcast function } \\
\text { remote control module }\end{array}$ \\
\hline $\begin{array}{l}\text { Set-top boxes and } \\
\text { Middleware API }\end{array}$ & $\begin{array}{l}\text { - set-top box linkage for high-quality video transmission } \\
\text { - transmit data, music downloads and exclusive view module } \\
\text { - H.264/SMV2 high-definition video program[5][6] } \\
\text { - multi-functional Middleware interface API }\end{array}$ \\
\hline $\begin{array}{l}\text { Interlocking technologies of } \\
\text { various devices and contents }\end{array}$ & $\begin{array}{l}\text { - interlocking technologies provided and applied for various purposes depending on the type of } \\
\text { contents and device } \\
\text { - Default management, subtitle management, equipment management and content management }\end{array}$ \\
\hline
\end{tabular}

To implement the proposed system, the system should be inpplemented to provide services by centralized group management of multicasting large amounts of data.

\subsection{Definition of System Requirements}

\subsubsection{Real-time Control of Remote Devices and Contents}

This feature provides a control module for emergency / reservation / common / individual scheduling, real-time monitoring, fault and distribution management, broadcasting and remote control. Specific requirements are listed in Table 2

\section{Table 2. Requirements for real-time control of remote devices and contents}

\begin{tabular}{|c|c|}
\hline Function & Requirements \\
\hline Scheduling & $\begin{array}{l}\text { - Schedule registration, delete ang modify (year / month / day / hour / min / sec, auto start time input, content } \\
\text { classification content selection/display mode/playback time, WYSIWYG) } \\
\text { - Common or individual schedules, p piority setting and set period of schedule application }\end{array}$ \\
\hline $\begin{array}{l}\text { Equipment } \\
\text { control }\end{array}$ & $\begin{array}{l}\text { - Energency distribution - individual or batch schedule distribution } \\
\text { - Individual or batch subtitles on / off / distribution / private / batch } \\
\text { - Subtitle placement-TOP/MID/BTM [7][8] } \\
\text { - Individual or batch TJS transmission, processing status (wait - processing - complete) and equipment on / off }\end{array}$ \\
\hline $\begin{array}{c}\text { Fault } \\
\text { management }\end{array}$ & $\begin{array}{l}\text { - Alert and notice the personnel in case of failure } \\
\text { - Program forilue, recovery function }\end{array}$ \\
\hline Monitoring & $\begin{array}{l}\text { - Schedule information by equipment status and time, classified state of individual or batch schedule } \\
\text { - Remote access and control for device }\end{array}$ \\
\hline
\end{tabular}

\subsubsection{Settop Box Middleware API}

This muti-functional API controls the viewer, server and device with a variety of contents, and its detailed requirements are listed in Table 3.

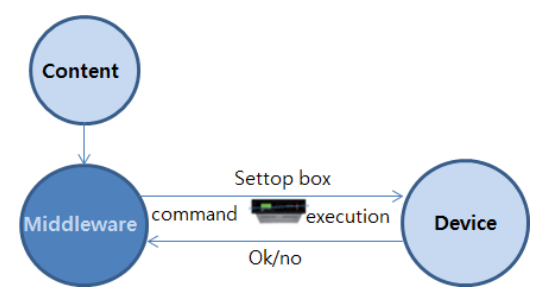

Figure 3. Settop Box Middleware 
Table 3. Requirements for Settop Box Middleware API

\begin{tabular}{|c|c|}
\hline Function & Requirements \\
\hline Settop Box & - Transmitting high-definition video only settop box \\
\hline $\begin{array}{l}\text { Transfer data, music downloads } \\
\text { and exclusive viewer module }\end{array}$ & $\begin{array}{l}\text { - Image viewer, video viewer, TEXT viewer, PPT viewer, PDF viewer, HWP viewer, music } \\
\text { playback }\end{array}$ \\
\hline Video program & - H.264/SMV2 high-definition video program[9] \\
\hline Middleware interface API & $\begin{array}{l}\text { - Upload/download/reserved downloads } \\
\text { - Broadcasting video files, music broadcasting, general broadcasting } \\
\text { - Information transmission to specific devices through batch broadcasting } \\
\text { - Displaying the announcement broadcast first when sending a broadcast } \\
\text { - Interlocking with server Middleware } \\
\text { - Display control / power on / off control } \\
\text { - Equipment interface module for distributing transmitted data }\end{array}$ \\
\hline
\end{tabular}

This chapter describes the design and implementation of the integrated control system suggested in this paper. The integrated control system is divided into three major programs: real-time control technology development of remote devices and contents, API development of settop box Middleware and interloeking technology development of various devices and contents. The core technology for implementing these three programs is to enable the system to provide its services by centralized group management of multicasting large amounts of data.

That is, the system sets indiyidual or batch schedules for playing large multimedia data at many different remote devices and then performs multicasting. If an emergency occurs afterward, the system sends a batch announcement or emergency message to all remote devices connected. This is the system to be implemented with such services through centralized group management.

Thus, in this chapter the design and implementation of the Middleware and centralized group management for multicasting are described.

\subsection{Multicast Middleware}

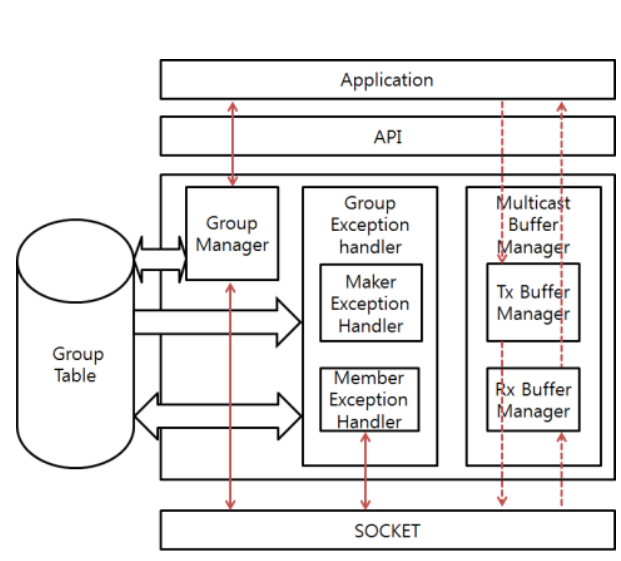

Figure 5. Middleware Architecture of Group creator

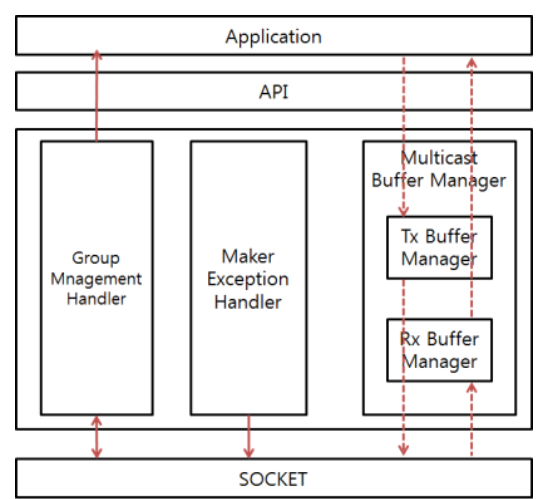

Figure 6. Middleware Architecture of Group Members 
The module for integrity and control of remote terminal devices using this Middleware is managed by multicast group management at the administrator PC, and heterogeneous terminal devices join into or withdraw from the group passively by the group management at the administrator PC.

Multicast Middleware consists of a group creator and Middleware for group members as shown in Figure 5 and Figure 6 respectively. The roles of each module in brief are as follows:

(1) API: This provides a program interface to enable the application to use functions of the Middleware. The main APIs provided are listed in Table 4.

Table 4. Multicast Middleware API

\begin{tabular}{|c|l|}
\hline Development & \\
\hline \hline MakeMcastGroup() & Create a multicast group \\
\hline GroupModifySend() & Add or delete a member to or from the/multicast group \\
\hline CloseGroup() & Delete the multicast group \\
\hline McastSend() & Transmit multicast data \\
\hline LargeMcastSend() & Transmit large multicast data \\
\hline McastRecv() & Receive multicast data \\
\hline
\end{tabular}

(2) Group Manager and Group Mandgement Hanđer: the group manager in the group creator writes a generation, modification or deletion message of a multicast group and sends it the relevant group members. Meanwhile the group management handler in each group member joins into or withdraws from the group

(3) Group Exception Handler and Member Exception Handler: These are required to recover the multicast group information, when restarted due to abnormal termination. The group creator saves each group management operation into a file, and retrieves the group information from the file by the makgr exception handler. A group member requests group information through the member exception handler, and the requested group creator recovers the group information on the reception of a registration message from the corresponding group.

(4) Multicast Buffer Manager: This performs multicast transmission and reception of large data. Since the multicast uses UDP for transport layer [10], separate management of buffer transmission and reception is needed for data over $64 \mathrm{~KB}$. To this end, the multicast buffer manager performs fragmentation and defragmentation for large data over $64 \mathrm{~KB}$.

\section{Conclusion}

The system proposed in this paper is the system, which can integrate and control remote terminal devices, is implemented as a multicast, At the center directly controlled various devices and APIs such as settop boxes, kiosks and speakers at many different remote locations, as well as their functions including broadcast scheduling and editing, automatic multimedia playback and subtitle display configuration, for each heterogeneous device. The system has been developed on the Middleware for multicasting large amounts of data and the algorithm of centralized group management.

By providing integrated services such as a variety of device inputs and information outputs and management of server for stable transmission process, the base platform was implemented where information in various formats can be transmitted in the heterogeneous devices. In addition, the key technologies include mapping of different devices and media 
objects, playback, conversion and audio processing for numerous media files, asynchronous messaging between the server and the client, and Middleware implementation.

\section{References}

[1] V. Fodor, et al., "Resilience in live peer-to-peer streaming", IEEE Communications Magazine, vol. 45, no. 6, (2007) June.

[2] G. Tan, et al., "Improving the Fault Resilience of overlay multicast for media streaming", vol. 15, no. 3, IEEE Transactions on Networking, (2007) June.

[3] X. Jin, W. -P. K. Yiu and S. -H. G. Chan, "Loss Recovery in Application-Layer Multicast", IEEE Multimedia Magazine, vol. 5, no. 1, (2008).

[4] Jarvis, et al., "Performance Analysis and Improvement of Overlay Construction for Peer-to-Peer Live Streaming", SIMULATION, vol. 82, Issue 2, (2006) February, pp. 93-106.

[5] X. R. Xu, A. Myers, H. Zhang and R. Yavatkar, "Resilient multicast support for continuous-media applications," in Proceedings of NOSSDAV' 97, (1997) May.

[6] W. -P. K. Yiu, et al., "Lateral Error Recovery for Media Streaming in Applicatiøn-Level Multicast", vol. 4, IEEE Tran. on Multimedia, (2006) April.

[7] E. Pournaras, M. Warnier and F. M. T. Brazier, "Self-optimised Tree Overlays using Proximity-driven Selforganised Agents.pdf”, Complex Intelligent Systems and Thei Ápplications Spynger Optimization and Its Applications, vol. 41, (2010), pp. 137-161.

[8] X. Jin, W. -P. K. Yiu and S. -H. G. Chan, "Loss Recovery in Application-Layer Multicast", MultiMedia, IEEE, vol. 15, Issue 1, (2008), pp. 18-27.

[9] Jarvis, et al., "Constructing Reliable and Êfficien Overlays for P2P Live Media Streaming", I.J. of SIMULATION, vol. 7, no. 2, (2006), pp. 54-62.

[10] J. -I. Park and J. -T. Choi, "Development of Module for Integrating and Controlling, Multimedia Contents and Remote Terminal Devices Based or Marlticast", Advaneed Science and Technology Letters, vol. 43, Multimedia, (2013), pp. 47-51.

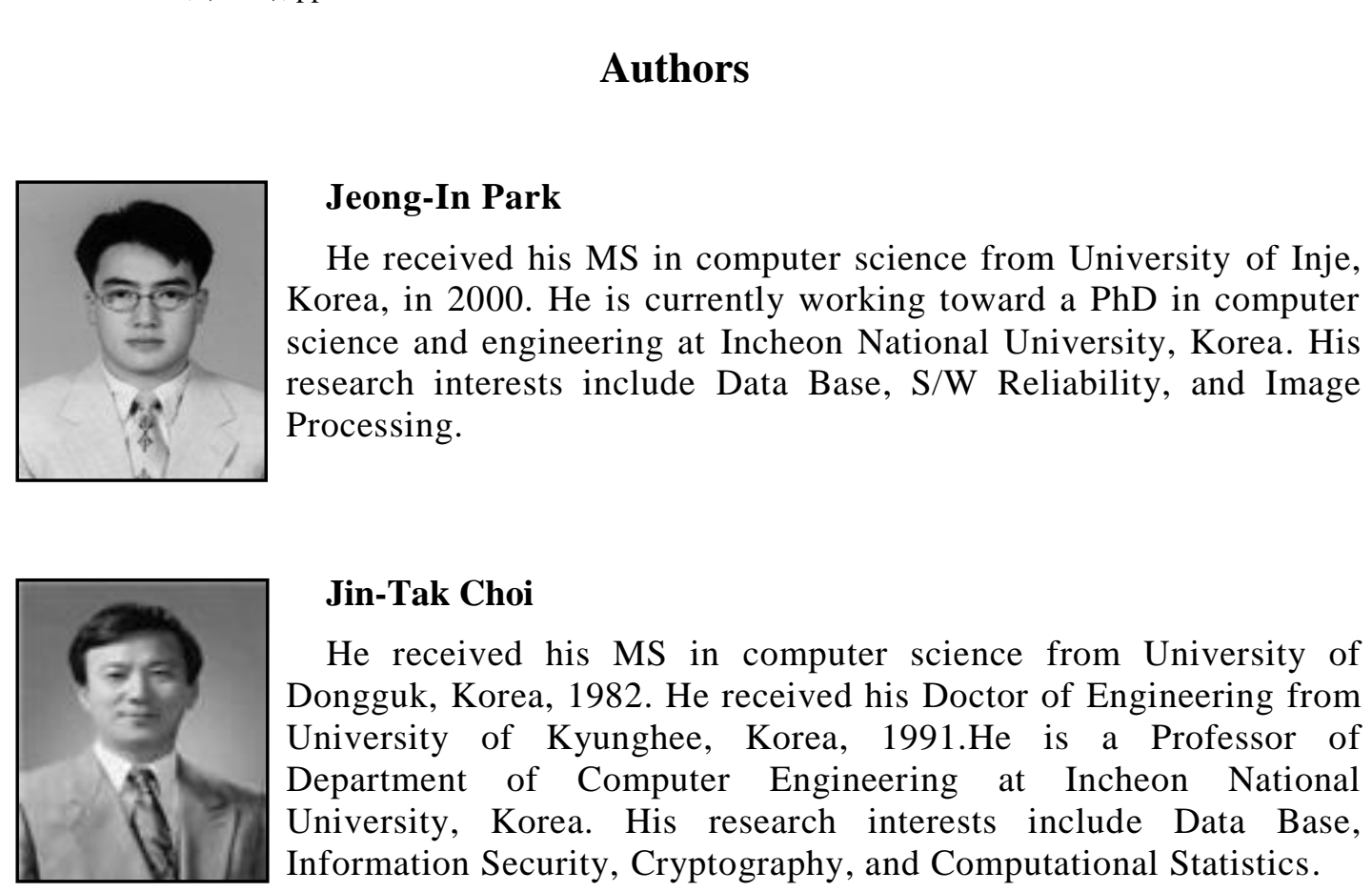

